\title{
Role of osteocytes in the adaptation of bone to mechanical loading
}

\section{Astrid D Bakker \& Jenneke Klein-Nulend ${ }^{\dagger}$}

${ }^{\dagger}$ Author for correspondence: ACTA-Vrije Universiteit, Department of Oral Cell Biology, Van der Boechorststraat 7. NL-1081 BT Amsterdam, The Netherlands m Tel. : +31 204448660 m Fax: +31 204448683

- $\mathrm{j}$. kleinnulend@vumc.nl

The mechanical performance of our skeleton is secured by the constant adaptation of bone to its mechanical loading environment. Mechanical adaptation of bone is brought about by the coordinated actions of osteoclasts and osteoblasts, which are orchestrated by the most mechano-sensitive cells in bone, the osteocytes. Loading on bone generates a flow of interstitial fluid through the lacuno-canalicular network in which the osteocytes are positioned. This flow is sensed by the osteocytes, which respond by the release of signaling factors such as nitric oxide, prostaglandins and Wnts, which alter the recruitment and activity of osteoblasts and osteoclasts, thereby affecting bone mass. Thus, any factor that alters the response of osteocytes to mechanical loading potentially affects bone mass. This paradigm could have implications for the field of rheumatology, where proinflammatory cytokines might affect bone mass by altering the response of osteocytes to mechanical loading.

The vertebrate skeleton performs a variety of functions, of which the relative importance will change depending on environmental circumstances. The functions of the skeleton include the provision of space for hematopoiesis, the protection of the soft organs and the regulation of calcium homeostasis. Lately, evidence is accumulating for an important role of the skeleton in phosphate homeostasis as well. The most important task of the skeleton, however, is to provide mechanical support, in order to withstand the force of gravity, and to support muscle forces allowing movement. This function is secured by the constant adaptation of bone to its mechanical loading environment. That bone adapts its mass and structure to mechanical loading has been extensively demonstrated [1-6]. Therefore, it is now common knowledge that increased mechanical loading (e.g., due to exercise) increases, and unloading (e.g., due to bedrest) decreases bone mass, mineral content and bone matrix protein production. This phenomenon is known as functional adaptation of bone, and it serves to obtain bones that combine a proper resistance against mechanical failure with a minimum use of material. More than 20 years ago, Frost postulated his mechanostat theory that predicts that there are threshold levels of mechanical strain, above which adaptive bone formation is activated, and lower levels, below which bone resorption is activated [7]. What is interesting about this mechanostat theory is that these threshold levels (or setpoints) can shift under the influence of agents such as hormones. Such agents would then affect bone mass in a way that resembles the effect of mechanical (un)loading [7]. According to the mechanostat theory, bone loss takes place owing to the activation of bone remodeling below a certain mechanical stimulation. Indeed, it is likely that the actual adaptation of bone to the ever changing mechanical demands takes place during the complicated process of bone remodeling $[2,8]$. However, bone remodeling takes place continuously, and depending on the balance between bone formation and resorpion within the newly formed osteons, bone mass can be lost or gained.

\section{Bone remodeling}

Often bone is thought of as a dead tissue, consisting solely of calcified matrix, but the opposite is true. Human bone contains over 15,000 osteocytes per $\mathrm{mm}^{3}$, and mouse bone contains even more than 60,000 osteocytes per $\mathrm{mm}^{3}$ of matrix [9,201]. Bone is not a static tissue either. As a matter of fact, old bone is constantly being removed by osteoclasts and replenished by osteoblasts in a coordinated fashion. This process, known as bone remodeling, presumably serves to prevent or remove microscopic damage in the matrix that occurs owing to continuous wear and tear. The constant renewal of bone also aids the adaptation of bone to its mechanical environment. It allows the osteoclasts to remove excess bone in places that are relatively unloaded, and the osteoblasts to add bone in places that are exposed to relatively high levels of loading.

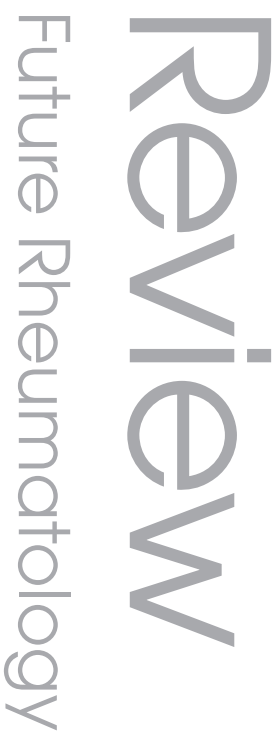

\section{Keywords}

bone remodeling = fluid flow - mechanical adaptation

- mechanosensing

- mechanotransduction

- osteocyte

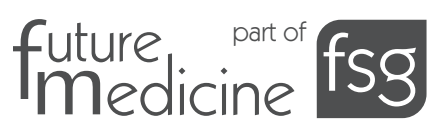


The microscopic damage that occurs owing to tissue fatigue is assumed to be the actual signal for activation of the process of bone remodeling [10-12]. Fatigue damage will likely promote osteocyte apoptosis, which attracts osteoclasts, thereby activating bone remodeling [11-13]. After activation, bone remodeling involves groups of osteoblasts and osteoclasts, which collaborate in a tightly coordinated fashion in so-called basic multicellular units (BMUs) [14]. Within these BMUs, the osteoclasts excavate a tunnel in the compact bone, or a trench along the surface of trabeculae. The osteoclasts are closely followed by osteoblasts that refill the tunnel [15]. The osteoblasts frequently bury one of themselves in the newly formed matrix, thereby forming the new osteocytes [16,17]. The entombed cells assume a stellate shape, with cell bodies positioned in lacunae in the matrix, from which slender cell processes radiate in all directions. The cell processes pass through the bone matrix via small canals, the canaliculi, in order to keep in contact with other osteocytes and the cells outside the bone matrix. The osteoblasts do not completely fill the tunnel that is excavated by the osteoclasts, but a space is left in the middle for blood vessels, providing the osteocytes with nutrients and oxygen [15]. This way, osteons are formed, containing osteocytes at a maximum of six cell layers deep, and a blood vessel in the middle (Figure 1).

\section{Mechanical loading drives interstitial fluid flow}

It is generally assumed that the coordinated cooperation of osteoclasts and osteoblasts during bone remodeling and mechanical adaptation is orchestrated by the osteocytes, which are able to respond to mechanical signals [18-20]. Yet, it has long been a matter of debate how mechanical loading of intact bone is transduced into a signal that is able to activate the osteocytes. The application of mechanical loads on bone during physical activity results in several potential cell stimuli. These include changes in hydrostatic pressure, direct cell strain, fluid flow and electric fields resulting from electrokinetic effects accompanying fluid flow [21]. In healthy, adequately adapted bone, strains as a result of physiological loads (e.g., resulting from normal locomotion) are quite small. Quantitative studies of the strain in bones of animals and humans found a maximal strain not higher than $0.2-0.3 \%[22,23]$. It might be that these strains are high enough to to be sensed directly by osteocytes. Vatsa and colleagues hypothesized that if osteocytes can sense matrix strains directly, the cell shape, cytoskeletal alignment and distribution of adhesion sites in osteocytes in situ will bear alignment to the mechanical loading patterns [24,25]. Indeed, using confocal laser scanning microscopy, they found that the cell shape and distribution of actin

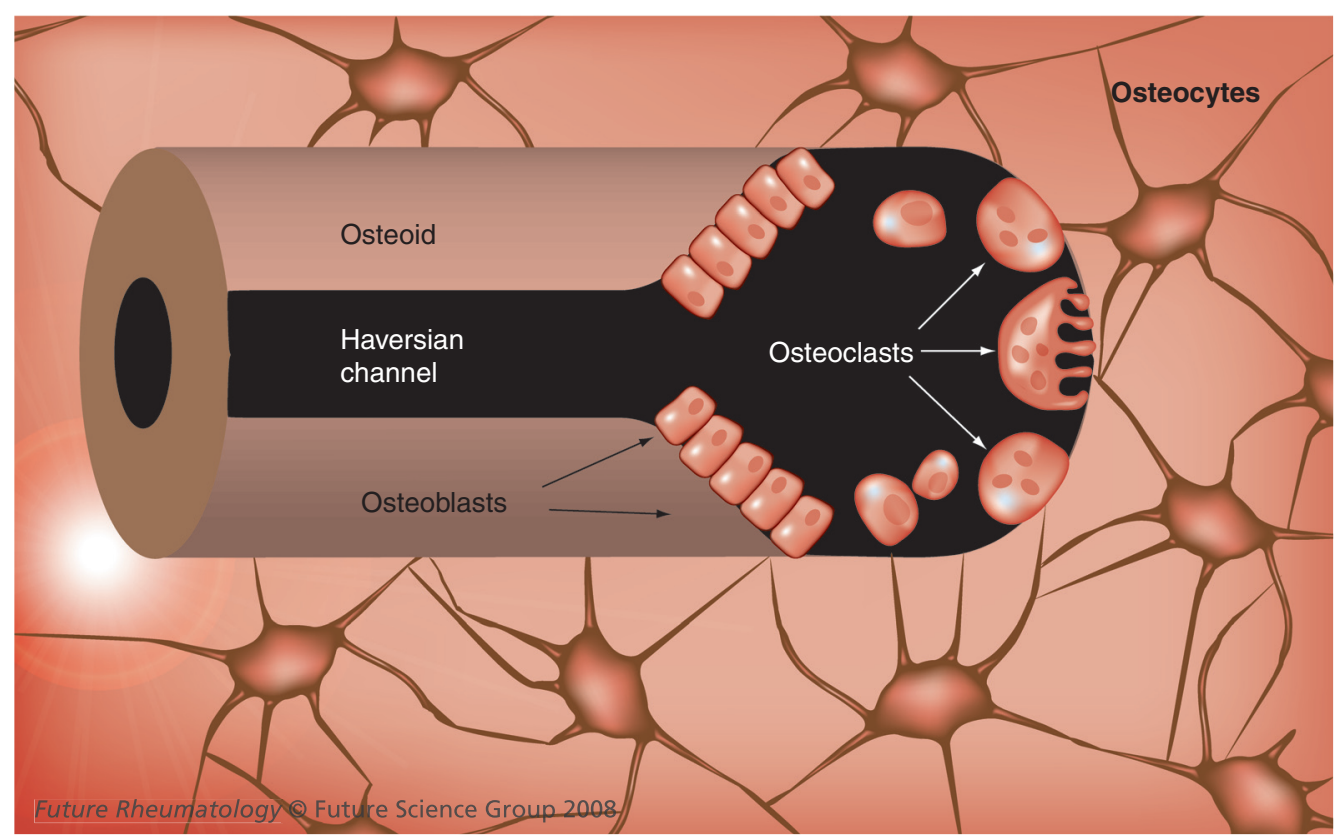

Figure 1. Osteonal tuneling. Fatigue damage promotes osteocyte apoptosis, which attracts osteoclasts, thereby activating bone remodeling. After activation, osteoclasts excavate a tunnel in compact bone and are closely followed by osteoblasts that refill the tunnel. The osteoblasts frequently bury one of themselves in the newly formed matrix, thereby forming the new osteocytes. The osteoblasts do not completely fill the tunnel that is excavated by the osteoclasts, but a space is left in the middle for blood vessels. 
and paxillin in osteocytes of mouse tibiae and calvariae reflected the respective mechanical loading patterns in these bones [24,25]. This suggests that osteocytes might be able to directly sense matrix strains due to external loading of bone.

However, if we accept that bone organ strains are extremely small, then it is an attractive idea that bones possess an amplification system whereby small matrix strains are transduced into a larger signal that is easily detected by osteocytes. The canalicular flow hypothesis proposes such an amplification system. In this theory, the small matrix strains are sufficient to drive the thin layer of interstitial fluid surrounding the osteocytes to flow from regions under high pressure to regions under low pressure [18,19,26-31]. The flow of fluid gives rise to a mechanical signal that activates the osteocytes. The theoretical model, which makes the flow of extracellular tissue fluid through the lacuno-canalicular network as a result of bone tissue strains plausible, was described more than 30 years ago by Piekarski and Munro [32], and has meanwhile been shown to occur experimentally [30,33]. It is notheworthy that the kind of mechanical stimuli that would drive a fluid flow (i.e., high-amplitude, low-frequency strains) are extremely rare in the activities of daily life, whereas high-frequency (up to $40 \mathrm{~Hz}$ ), low amplitude $(<0.001 \%)$ stimuli are common [34]. This does not mean that interstitial fluid flow is not important for the osteogenic response of bone to mechanical loading. As a matter of fact, (static) loading regimes that do not elicit fluid flow through the lacuno-canalicular network do not seem to be osteogenic [35]. The most osteogenic are loading regimes that are dynamic, which elicit high strain rates and thereby presumably strong flow of interstitial fluid in bone [36]. As strain rate is determined by both the magnitude of the strain and the frequency of the stimulus, both magnitude and frequency of loading are important parameters for bone formation. Using strain sensors in hip implants of humans [37], it has been calculated that the frequency spectra of the forces on the hip shows a rich harmonic content ranging between 1 and $3 \mathrm{~Hz}$ for walking cycles and reaching $8-9 \mathrm{~Hz}$ for running cycles [38].

\section{Fluid flow activates osteocytes}

If osteocytes do not directly sense the loadinginduced strain of the bone matrix, but rather respond to the strain-induced flow of interstitial fluid along the network of osteocytes, then what is the flow-derived mechanical stimulus that activates the cells? By comparing variations in fluid transport with variations in wall shear stress, it was shown that the stimulus that activates primary bone cells or osteoblasts in vitro is fluid shear stress rather than streaming potentials or chemotransport [39,40]. Whether these observations can be extrapolated towards osteocytes that are embedded in a 3D matrix is a matter of debate. In this light it is noteworthy to mention that results obtained with osteoblasts as a model for mechanosensitive bone cells subjected to oscillating fluid flow, suggested that depriving the cells of nutrients reduces the response to the mechanical stimulus. This indicates that chemotransport could also play a role in mechanotransduction [41]. In any case, it has been predicted that fluid induced shear stresses over the cell extensions of osteocytes in vivo will be in the order of magnitude of $8-30 \mathrm{dyn} / \mathrm{cm}^{2}$ [29]. Although both the accuracy and the relevance of these calculations are currently under debate, it is noteworthy that bone cells in vitro seem to be highly sensitive to shear stress in the order of this magnitude.

Recently, insights into the flow-derived stimulus that activates the osteocyte in vivo have been evolving. While it is still generally assumed that the flow-derived stimulus is the wall shear stress over the cell membrane, the tensile forces on the cell due to the drag forces on the fibers that tether the osteocyte process to the wall of the canaliculus may be more important for transducing whole bone loads into a stimulus for osteocytes, since these tensile forces are many times greater than the fluid shear stresses [31,42]. Recently it was suggested that the osteocyte processes might be attached directly to the canalicular wall by $\beta 3$ integrins at the apex of infrequent, previously unrecognized canalicular projections. A theoretical model was developed, which predicts that the tensile forces acting on these integrins are less than $15 \mathrm{pN}$, and thus provide stable attachment for the range of physiological loadings. The model also predicts that axial strains caused by the sliding of actin microfilaments are two orders of magnitude greater than whole-tissue strains. In vitro experiments indicated that membrane strains of this order are large enough to open stretch-activated cation channels [43]. Although it is yet to be determined what the exact mechanical stimulus is for osteocytes in vivo, there is a general consensus that this stimulus is likely derived from strain-derived flow of interstitial fluid.

\section{Osteocytes transduce mechanical stimuli into chemical signals}

After the fluid flow-derived mechanical stimulus has reached the osteocyte, it is translated into a 
biochemical signal. Cellular features that likely play a role in the process of mechanotransduction are stretch-activated ion-channels, integrins, the cytoskeleton and possibly primary cilia.

As previously mentioned, the integrin-cytoskeleton complex may play a role as an intracellular signal transducer for stress signals. In addition to integrins, the nonintegrin adhesion receptor CD 44 may attribute to the attachment of osteocytes to the surrounding matrix. CD44 is present in abundance on the osteocyte surface $[44,45]$, and is also linked to the cytoskeleton. Several studies suggest that the attachment complex between intracellular actin cytoskeleton and extracellular matrix macromolecules, via integrins and CD 44 receptors in the cell membrane, provides the site of mechanotransduction in osteoblasts as well as osteocytes [46-50].

Lately, evidence is accumulating underscoring the crucial role of the cytoskeleton for a multitude of cellular processes. The cytoskeleton, just like our bony skeleton, provides structure and support for the cell, is actively adapted and is highly responsive to external physical and chemical stimuli. The cytoskeleton is strongly involved in processes such as migration, differentiation, mechanosensing and even cell death, and largely determines the material properties of the cell (i.e., stiffness). Typical features of the osteocyte cytoskeleton are the prominent actin bundles in the osteocytic processes, together with the abundant presence of the actin-bundling protein fimbrin [51,52].

From the field of physics, it is known that the effect of stresses applied at different rates at an object are largely determined by the material properties of that object. For cells, the material properties are to a large extent determined by the cytoskeleton. For osteoblasts, it was shown that the production of signaling molecules correlated with the applied stress rate [38,53-55]. This suggests that the response of osteoblasts to loading is related to cytoskeletal properties. Although the cytoskeleton of osteoblasts and osteocytes show clear differences, for instance, in the expression of actin-binding proteins [51,56], it seems likely that the response of osteocytes to loading is also related to cytoskeletal properties. Indeed, it has been described that osteocytes under round-suspended morphology were an order-of-magnitude more elastic compared with flat-adherent cells, and required lower force stimulation in order to show an increase in nitric oxide $(\mathrm{NO})$ production [57], indicating that cytoskeletal properties of the cell affect the ability for mechanosensing. This is confirmed by in vitro experiments demonstrating that cytoskeletal disruption reduces the response of osteocytes and osteoblasts to mechanical loading $[48,58,59]$. Since cytoskeletal properties of the cell affect the ability for mechanosensing, and since osteocytes are more responsive to mechanical stress than osteoblasts [26], this might be directly related to the different cytoskeletal properties of osteoblasts and osteocytes. The different cytoskeletal properties indeed seem to be reflected by the decrease in elastic modulus as bone cells mature from osteoblasts to preosteocytes and osteocytes [60]. On the other hand, a different study reported that flat adherent MLO-Y4 cells, primary chicken osteocytes, MC3T3-E1 osteoblasts, and primary chicken osteoblasts all showed a similar elastic modulus of less than $1 \mathrm{kPa}$ [61]. This indicates that differences in mechanosensitivity between cells might not be directly related to the elasticity of the cell, but might be more related to other cell-specific properties, such as the presence of receptors or ion channels in the membrane.

Studies on the mechanical properties of osteocytes have been performed on flat, adherent cells. Under this condition, the properties of osteocytes might not reflect the true osteocyte properties when assuming their unique 3D morphology. Moreover, it is debatable whether mechanical properties of the cell body are of relevance, since mechanical loading in vivo might mostly affect the cell protrusions of the osteocytes, be it via drag forces on the cell membrane, hoop strain or direct activation of integrins. As such, the osteocyte processes can be considered parts of the cell that not only allow cell-to-cell communication and possibly matrix mineralization, but can also be considered the predominant cell organ that allows mechanosensing. The differentiation marker protein E11/gp38 is a protein expressed by osteocytes in vivo that appears to be responsible for the formation of dendritic processes [62]. This molecule might thus also be of utmost importance for the ability of osteocytes to sense mechanical loading. Culture experiments with isolated osteocytes have shown that although the cells lose their stellate shape in suspension, they re-express this morphology as soon as they settle on a support (Figure 2) [63]. Apparently, the typical stellate morphology is an intrinsic characteristic of terminal osteocyte differentiation.

In bone, gap junctions are present between the tips of the cell processes of connecting osteocytes [64], thereby forming a network of gap junctioncoupled cells. Gap junctions are transmembrane channels connecting the cytoplasm of two adjacent cells and regulating the passage of molecules 
less than $1 \mathrm{kDa}[65,66]$. Gap junction channels are formed by members of a family of proteins known as connexins. One of these members, connexion 43 (Cx43), appears to play an important role in bone cells, as Cx43-null mice have delayed ossification, craniofacial abnormalities and osteoblast dysfunction [67]. It has been proposed that gap junctions function through the propagation of intracellular signals contributing to mechanotransduction in bone, thereby regulating bone cell differentiation [68]. A dominant negative mutant of $\mathrm{Cx} 43$ diminishes fluid flowinduced release of $\mathrm{PGE}_{2}$, but not $\mathrm{Ca}^{2+}$ responses [69]. Fluid flow-induced shear stress stimulates gap junction-mediated intercellular communication and increases $\mathrm{Cx} 43$ expression in MLO-Y4 cells [70], while oscillating fluid flow has been shown to upregulate gap junction communication by an ERK1/2 MAP kinase-dependent mechanism in MLO-Y4 osteocytes [71].

Besides gap juctions, osteocytes posess hemichannels, unapposed halves of gap junction channels, that localize at the cell surface [72]. Primary osteocytes and MLO-Y4 osteocytelike cells [73] express very large amounts of Cx43 compared with other cell types such as osteoblasts, yet these cells are only in contact through the tips of their dendritic processes, raising the question regarding the function of Cx43 on the rest of the cell membrane. It has been shown that oscillating fluid flow activates hemichannels in MLO-Y4 osteocyte-like cells, but not in MC3T3-E1 osteoblast-like cells [74]. Hemichannels expressed in bone cells such as MLO-Y4 osteocytes appear to function as essential transducers of the anti-apoptotic effects of bisphosphonates [75], and serve as a portal for the exit of elevated intracellular $\mathrm{PGE}_{2}$ in osteocytes induced by fluid flow shear stress [76].

Another cellular feature that might play a role in the process of mechanotransduction is the primary cilium. It has recently been shown that osteocytes express a single primary cilia [77], and that PKD1/PC1, a mechanosensory protein in the kidney that localizes to primary cilia, is known to play a role in normal bone structure. MC3T3-E1 osteoblasts and MLO-Y4 osteocytes possess primary cilia that project from the cell surface and deflect during fluid flow [78]. These primary cilia were required for osteogenic and bone resorptive responses to dynamic fluid flow, such as the expression of osteopontin, prostaglandins and RANKL. The translation of fluid flow into bone cellular responses appeared to be independent of calcium- and stretch-activated ion channels [78]. It should be noted, however,
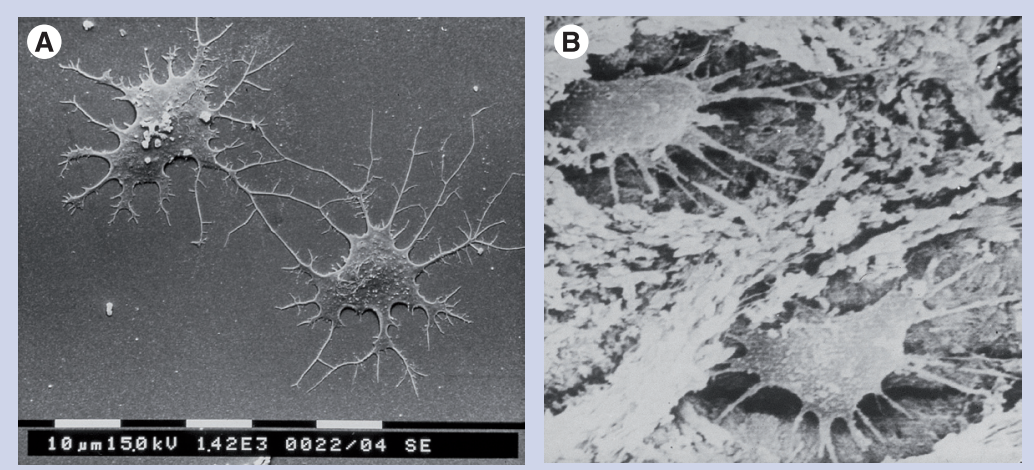

Figure 2. Osteocyte morphology. (A) Isolated osteocytes in culture maintain their typical in vivo phenotype, with cell fingers radiating in all directions. The typical stellate morphology might thus be an intrinsic characteristic of terminal osteocyte differentiation. (B) Osteocytes embedded in calcified bone. Note the many cell fingers, radiating from the osteocyte cell bodies that might have an important function in mechanosensing. Scanning electron microscopy pictures (original magnification: $\times 1000$ ).

that the role of the osteocyte primary cilium for mechanosensing in vivo is still under debate, as the space between the osteocyte cell membrane and lacunar surface is several-fold smaller than the length of a cilium, making it unlikely that it can deflect.

\section{Osteocytes release signaling molecules in response to mechanical loading}

So far we have described that bone remodeling serves to adapt bone mass and structure to the mechanical demands. We have emphasized that osteocytes play a pivotal role in this process, by sensing the mechanical stimulus and translating it into a chemical signal. We will now describe the nature of some of these chemical signals, and the effect of these chemical messenger molecules on the cells that actually change bone mass, in other words, the osteoclasts and osteoblasts.

An important early response to mechanical loading is the influx of calcium ions through mechanosensitive ion channels in the plasma membrane and the release of calcium from internal stores [31,49,79-82]. The resulting rise in intracellular calcium concentration is necessary for activation of calcium/calmodulin-dependent proteins, and activates many downstream signaling cascades, such as protein kinase $\mathrm{C}$ and phospholipase $\mathrm{A}_{2}$. Calcium/calmodulin-dependent enzymes that are activated by flow-induced rises in intracellular calcium include endothelial NO synthase (NOS), the enzyme responsible for loading-induced $\mathrm{NO}$ production. The activation of phospholipase $\mathrm{A}_{2}$ results in increased arachidonic acid release and $\mathrm{PGE}_{2}$ production [49]. Calcium also affects prostaglandin release by 
bone cells in an alternative manner, as it has been shown that fluid flow activates L-type voltagesensitive $\mathrm{Ca}^{2+}$ channels to promote $\mathrm{Ca}^{2+}$ entry. This stimulates vesicular ATP release, which in turn mediates flow-induced prostaglandin release via activation of purinergic receptors [83].

Prostaglandins are abundantly produced by osteocytes, as well as by other cells of the osteoblastic lineage [84-87], and play a key role in the bone formation response to mechanical loading in vivo [88,89]. Several studies have shown that osteocytes rapidly increase their prostaglandin production in response to mechanical loading in the form of a fluid flow in vitro [46,89]. Cyclooxygenase (COX) is the key enzyme involved in the production of prostaglandins [89], and exists in a constitutive (COX-1) and an inducible form (COX-2). Fluid shear stress does not affect COX-1 mRNA expression in primary human bone cells [90], but mechanical loading induces a rapid rise in COX-2 mRNA in human bone cells and chicken osteocytes in vitro, as well as COX-2 protein expression in rat bone cells in vivo [90-92]. Importantly, inhibition of COX-2, but not COX-1, inhibits fluid flow induced prostaglandin production by primary bone cells in vitro [93]. In addition, COX-2 has been shown to mediate the anabolic response of bone tissue to mechanical loading [64], illustrating the importance of loading-induced prostaglandin production for the process of adaptive bone remodeling. Besides purigernic receptors, prostaglandins are released through hemichannels in response to a mechanical stimulus [76].

Besides prostaglandins, NO release has also been shown to be essential for load-induced bone formation in vivo $[26,94,95]$. Several studies have shown that NO production is rapidly increased in response to mechanical stress in bone cells, including isolated osteocytes [38,53,96-98]. NO production has been widely used as a marker for studying the mechanosensitivity of osteocytes [96]. The intracellular upregulation of NO after mechanical stimulation has been shown in single bone cells using DAR-4M AMchromophore $[99,100]$. These studies also demonstrated that a single osteocyte can disseminate a mechanical stimulus to its surrounding osteocytes via extracellular soluble signaling factors $(\mathrm{NO})$, which reinforces the putative mechanosensory role of osteocytes [99]. The production of NO has been shown to be endothelial NOS dependent [101].

Another family of molecules that has very recently been identified as a mediator of the adaptive response of bone to mechanical loading is the Wnt family of proteins. The Wnt gene family represents a diverse group of secreted proteins that are potent modulators of cell behavior [102]. Wnt receptor complexes require the presence of a member of the Frizzled family of proteins [103], as well as the low-density lipoprotein receptor-related protein (LRP) 5 or 6 [104] for activation of canonical Wnt signaling. The simplified model for canonical Wnt signaling proposes that upon binding of the Wnts to both their receptors, $\beta$-catenin levels rise in the cytoplasm and form a complex with TCF/Lef1, which accumulates in the nucleus as a stable transcriptional regulator. Wnt signaling can also take place through kinases [105] and Wnts can activate GTPases, thereby modulating cytoskeletal organization [106]. In light of the role of the cytoskeleton in mechanosensing, it is noteworthy that Wnts may modulate cytoskeletal organization, and that $\beta$-catenin links cadherins to the actin cytoskeleton. Wnt signaling might be an important modulator of the process of mechano-regulated bone adaptation. This is illustrated by the finding that in vivo loading of mouse tibiae results in increased gene expression of Wnts and Wnt target genes including Wnt10B, SFRP1 and connexion 43. In addition, loading of tibiae by means of 4-point bending leads to more bone formation in mice with a dominantly active LRP5 receptor (resulting in a continuous activation of the Wnt signaling cascade) than in wildtype mice [107]. Similarly, it was found that the anabolic response of bone to mechanical loading was enhanced in ulnae of mice lacking the Wnt inhibitor Frzb [108]. Strikingly, the bones of these mice seemed to be more sensitive to mechanical loading, responding to stimuli that were not sufficient to elicit a response in wild-type mice. These findings were also supported by in vitro studies showing that MC3T3-E1 osteoblasts increased Wnt gene expression after mechanical stimulation by substrate deformation [109], and that $1 \mathrm{~h}$ of a mechanical stimulus in the form of a pulsating fluid flow (PFF) $(0.7 \pm 0.3 \mathrm{~Pa}, 5 \mathrm{~Hz})$ upregulated mRNA expression of $\beta$-catenin, APC and Wnt3a as well as the Wnt antagonist SFRP4 in MLO-Y4 osteocytes, at $0.5-3 \mathrm{~h}$ after cessation of the fluid flow stimulus [110], showing that osteocytes respond to mechanical loading with a modulation of expression of molecules involved in the wnt signaling cascade.

Sclerostin is a molecule that acts as a Wnt antagonist by binding the Wnt coreceptor LRP5 [111]. Sclerostin appears to be highly expressed in mature osteocytes compared with immature osteocytes [112]. Transgenic mice lacking sclerostin exhibit an increased bone mass, and the human condition of sclerostosis is due to 
a premature termination of the Sost gene [113], suggesting that sclerostin inhibits bone mass accrual. It has been suggested that sclerostin protein may be transported through canaliculi to the bone surface, where it inhibits bone formation by osteoblasts. Interestingly, Sost transcripts and sclerostin protein levels were dramatically reduced in osteocytes after loading of mouse ulnae in vivo. The magnitude of the strain stimulus was associated with Sost staining intensity and number of sclerostin-positive osteocytes. Hindlimb unloading, on the other hand, yielded a significant increase in Sost expression in the mouse tibia [114]. Mechanical loading might therefore lead to an increase in Wnt signaling, thereby driving the mechanical adaptation of bone.

Interestingly, several molecules have been identified, of which the expression is modulated by mechanical loading and seems to be more or less specific for osteocytes. Matrix extracellular phosphoglycoprotein (MEPE), for instance, is highly expressed in osteocytes compared with osteoblasts. MEPE-null mice show increased bone formation and bone mass, as well as resistance to age-related trabecular bone loss [115], suggesting a role for MEPE in the regulation of bone homeostasis. It has been shown that MEPE expression is upregulated in a time-dependent fashion in alveolar osteocytes in response to mechanical loading applied by orthodontic tooth movement [116]

Dentin matrix protein 1 (DMP1) is another molecule that seems to be highly expressed in osteocytes compared with other cells types $[117,118]$. DMP1 expression increases two- to three-fold in osteocytes of the mouse ulna $24 \mathrm{~h}$ after a single $2.4 \mathrm{~N}$ load for $30 \mathrm{~s}$ at $2 \mathrm{~Hz}$ [119]. A potential role of DMP1 in osteocytes may be related to hydroxyapatite formation. DMP1 is specifically expressed along and in the canaliculi of osteocytes within the bone matrix [118]. The canaliculi and lacunae in bones of DMP1-null mice have a compromised structure, which can have implications for the amplification of load signals to the osteocytes [120].

Phex protein is found on the plasma membrane of osteoblasts and osteocytes [121]. The precise function of Phex is unclear, but it clearly plays a role in phosphate homeostasis and bone mineralization. Deletion of Phex, as well as deletion or mutation of the osteocyte marker DMP1, results in hypophosphatemic rickets [118]. Phex gene expression are increased in response to load [119], opening the possibility that not only bone mass, but also mineral metabolism is regulated by mechanical loading.

\section{Osteocytes orchestrate osteoblast \& osteoclast activity}

Loading-induced production of signaling molecules by osteocytes, likely serves to modulate osteoblast and osteoclast recruitment and activity (Figure 3). It is known that prostaglandins and Wnts can stimulate osteoblast recruitment and activity [122-124] and that prostaglandins can stimulate osteoclast activity [86], while Wnts and NO inhibit osteoclast activity [125,126]. Vezeridis and colleagues demonstrated that PFF-treated osteocytes in vitro produce factors that inhibit osteoblast proliferation and stimulate alkaline phosphatase activity, suggesting a stimulation of osteoblastic activity [127]. Similar results were shown by Taylor and colleagues who found that osteocytes exposed to a continuous fluid flow rapidly stimulate alkaline phosphatase activity in osteoblasts [128]. They also showed that the ability to mediate osteoblastic alkaline phosphatase levels in response to the application of fluid shear is a phenomenon unique to osteocytes, and is not reproduced by other mesenchymal cell types [128]. Interestingly, the stimulation of osteoblast differentiation as described by Vezeridis and

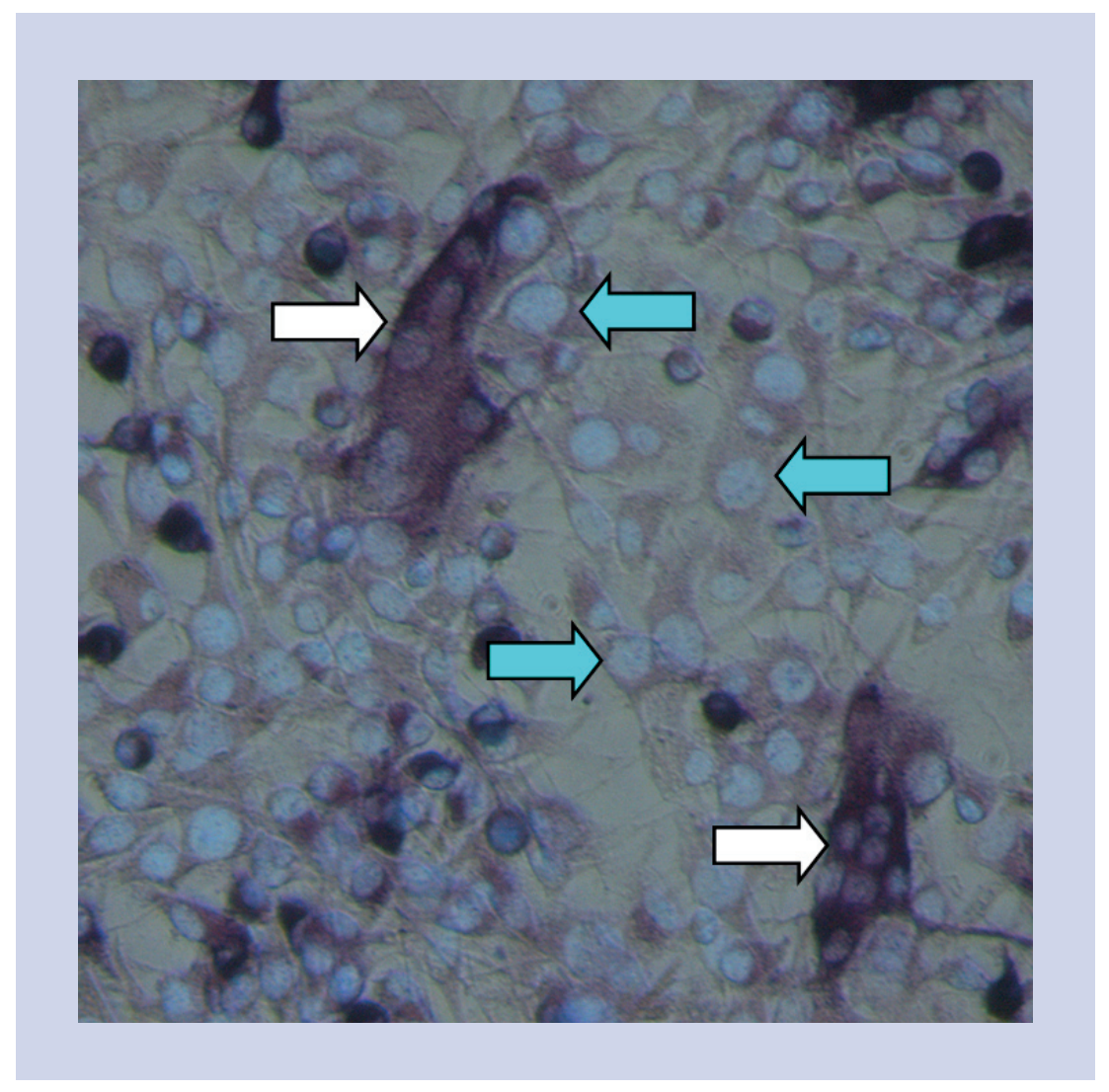

Figure 3. Osteocytes affect osteoclast development. Mouse bone marrow cells and MLO-Y4 osteocytes were co-cultured for 6 days. The number of multinucleated osteoclasts developing depends on the presence of live osteocytes.

Shaded arrows: osteocytes. White arrows: TRAP-positive multinucleated osteoclasts. 
coworkers [127] seemed to be NO-dependent, and did not require direct cell-cell contact. By contrast, Taylor and colleagues described that osteocyte-osteoblast physical contact via gap junctions is a prerequisite for stimulation of osteoblast differentiation by mechanically stimulated osteocytes [128].

Regarding osteoclast activity, it has been reported that MLO-Y4 osteocytes produce M-CSF, RANKL and Opg, and are able to actually promote osteoclast formation and activity under static culture conditions. The promotion of osteoclast formation required cell-cell contact, possibly owing to requirement of cell-bound RANKL [129,130]. By contrast, both Tan and colleagues [131] and You and coworkers [130] have shown that osteocytes subjected to mechanical loading by PFF actually inhibit osteoclast formation and resorption via soluble factors. Using primary osteocytes, Tan and colleagues demonstrated that the release of these factors was at least partially dependent on activation of an NO pathway in osteocytes in response to fluid flow [131]. In addition, You and coworkers showed that mechanical loading also decreases the potential of the osteocyte to induce osteoclast formation by direct cell-cell contact [130].

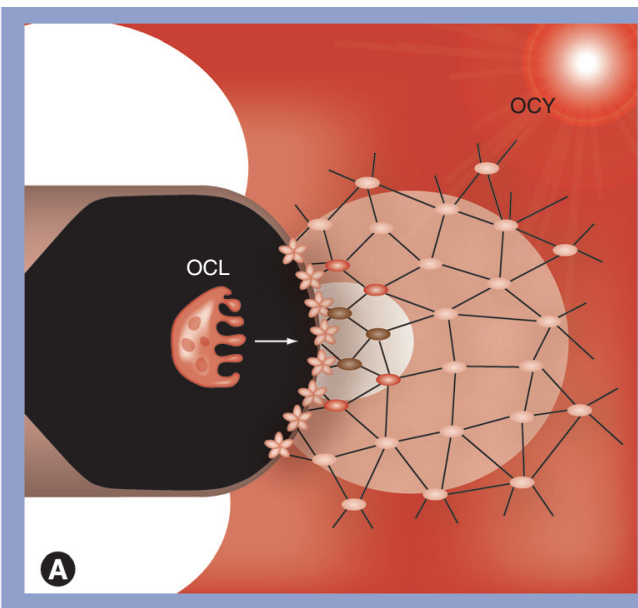

Burger and colleagues have developed a theory that links osteocyte sensing of different loadinginduced canalicular flow patterns around cutting cone and reversal zone during remodeling to the coordinated actions of osteoblasts and osteoclasts in a BMU [8,132]. Volumetric strain in the bone around a bone multicellular unit cutting cone has been related to canalicular fluid flow [133], and the predicted area of low canalicular flow around the tip of the cutting cone was proposed to induce local osteocyte apoptosis. Mechanical loading by fluid shear stress has been shown to promote osteocyte survival [134], while unloading is associated with osteocyte apoptosis [135]. Osteocyte apoptosis is a likely trigger for osteoclastic bone resorption, for instance via the release of alarmins such as HMGB1 [136], and very likely via apaoptotic bodies [137]. Osteocyte apoptosis at the tip of the cutting cone would thus attract osteoclasts, leading to further excavation of bone in the direction of loading. The model by Smit and colleagues further predicts that at the base of the cutting cone and further down the reversal zone, osteocytes receive enhanced fluid shear stress during loading [132]. This could prevent osteocyte apoptosis, but may also stimulate the

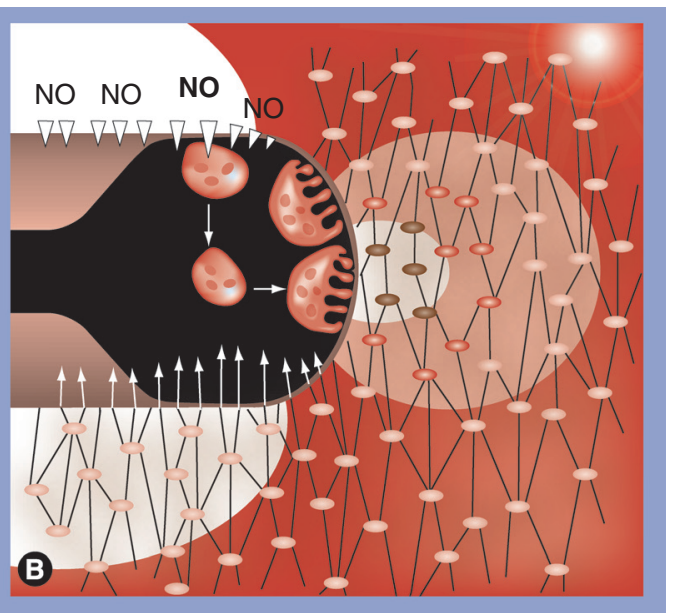

Figure 4. Basic multicellular unit-based bone remodeling orchestrated by

mechanosensitive osteocytes. (A) Representation of a basic multicellular unit (BMU). Osteocyte apoptosis (indicated as dark lacunae) is caused by lack of fluid flow at the tip of the cutting cone, where the matrix strains are relatively low during normal loading. Osteoclasts are attracted towards apoptotic osteocytes, and as a result the osteoclastic attack follows the direction of loading. (B) Representation of postulated events in the cutting cone of a progressing BMU. Osteoclasts are attracted by apoptotic osteocytes in the cutting cone tip, but forced to withdraw again from the bone surface at the cutting cone base, as a result of high amounts of NO produced by well-stressed osteocytes. As NO production remains high further down the reversal zone, osteoclasts remain within the cutting cone and may even re-enter the resorption cycle, leading to a 'treadmill' of active and inactive osteoclasts that together dig the resorption tunnel or trench. Vertical arrows indicate direction and magnitude of canalicular fluid flow; vertical arrow heads indicate release of NO by well-stressed osteocytes. Light colours denote places in the matrix that experience low strains during loading in the normal direction, while white areas denote areas of high strain. NO: Nitric Oxide; OCL: Osteoclast; OCY: Osteocyte network. Modified from [132]. 
release of signaling molecules that promote the retraction and detachment of osteoclasts from the bone surface. These two mechanisms, attraction of osteoclasts to the cutting cone tip and induction of osteoclast detachment from the cutting cone base, together could explain the mechanically meaningful behavior of osteoclasts during remodeling (FIGURe 4). Recently, a finite element-based computer model was developed for bone adaptation to mechanical loading [138]. The model was based on the mechanosensory function of osteocytes, in other words, strain-induced osteocyte signals inhibit bone resorption and stimulate bone formation, in order to investigate how this paradigm would affect BMU-based bone remodeling. The simulations showed that a strain-induced osteocyte signal can direct resorbing osteoclasts in the dominant loading direction, while unloading leads to abnormal resorption directions, as was predicted by Burger and colleages [8]. Under normal loading conditions the osteocyte signal-induced indirect coupling of formation to resorption [138]. The computer model thus shows that BMU-based bone remodeling, driven by input from mechanosensitive osteocytes, could explain bone adaptation to both loading and unloading.

In summary, it is generally assumed that loading on bone generates a flow of interstitial fluid through the lacuno-canalicular network. This flow is sensed by the osteocytes, which respond by the release of signaling factors. These signaling factors, including $\mathrm{NO}$, prostaglandins and Wnts, can alter the recruitment and activity of osteoblasts and osteoclasts, thereby affecting bone mass. Indeed, experiments employing targeted ablation of osteocytes in mouse bones revealed that viable osteocytes are required for transducing mechanical signals into a cellular response [139]. The osteocyte-less mice were resistant to unloading-induced bone loss, suggesting that viable osteocytes are necessary for activation of osteoclastic resorption in response to unloading. Strikingly, (re)loading-induced recovery of bone mass seemed to be unhampered, even when $80 \%$ of the osteocytes were dead [139]. If true, these remarkable results will have a great impact on current paradigms regarding loading-induced increase in bone mass.

If osteocytes indeed regulate bone mass by dictating the balance between bone formation and resorption in response to mechanical loading, any factor altering the response of osteocytes to mechanical loading potentially affects bone mass. Such an alteration of the mechano- sensitivity would be analogous to a change in setpoint for activation of bone formation or resorption, as described in the mechanostat theory by Frost [7]. One agent that has been suggested to alter the sensitivity of osteocytes to mechanical loading is estrogen. Estrogens have a strong effect on bone mineral density in humans [140,141], which could be explained on the one hand by direct effects of estrogen on osteoblasts and osteoclasts [142,143], and on the other hand by an alteration of response of bone cells to mechanical loading [144]. Opposing this latter explanation are several in vivo studies that were unable to detect a synergistic effect of estrogen and mechanical loading on bone formation $[140,141,145,146]$. However, it is striking that the anabolic response of bones to mechanical loading in vivo requires ER- $\alpha$ [147]. Expression of ER- $\alpha$ is affected by estrogen, which would be in-line with the hypothesis that bone loss associated with estrogen deficiency is a consequence of reduction in ER- $\alpha$ expression, reducing the effectiveness of the anabolic response of bone cells to strain [148]. However, the response of primary human bone cells to a mechanical stimulus in vitro was similar in magnitude in the presence and absence of estrogen [149]. Thus, although there is convincing evidence available for the role of ER- $\alpha$ in mechanotransduction by osteocytes, it has yet to be proven that estrogen affects the mechanical setpoint of bone.

\section{The role of osteocytes in inflammation-associated bone loss}

During inflammatory diseases such as rheumatoid arthritis (RA), the balance between bone formation and resorption is often disturbed, resulting in localized bone loss around the affected joints as well as generalized osteoporosis [150-153]. This bone loss is multifactorial, and might be caused by the physiological adaptation of bone to reduced physical activity that is common in patients with RA, or the use of corticosteroids by the patients. In addition, it is likely that proinflammatory cytokines, such as tumor necrosis factor (TNF)- $\alpha$ and interleukin (IL) $1-\beta$ that play an important role in the etiology of RA also contribute to this bone loss [154].

If cytokines decrease the mechanosensitivity of osteocytes, as has been suggested for estrogen [7], they could thereby contribute to the generalized bone loss in patients with RA. Indeed we recently found that both TNF- $\alpha$ and IL- $1 \beta$ inhibit the upregulation of $\mathrm{NO}$ production after mechanical stimulation by PFF [155]. This inhibition was associated with a prevention of 
fluid shear stress-induced $\left[\mathrm{Ca}^{2+}\right]_{\mathrm{i}}$ upregulation [155]. This provides a novel mechanism by which cytokines might interfere with bone remodeling during inflammatory diseases, via an effect on the mechanoresponse of osteocytes.

\section{Conclusion}

Significant progress has been made in the uncovering of the cellular and mechanical basis of the osteocyte's response to loading, and to our understanding of cellular mechanotransduction and bone remodeling. The 3D interconnected osteocyte network with its accompanying lacuno-canalicular porosity is the site of mechanosensing in bone tissue. Mechanotransduction then includes the translation by osteocytes of canalicular flow into cell signals that can alter the recruitment and activity of osteoclasts and osteoblasts. Osteoclastic bone resorption and osteoblastic bone formation could thus be related to different loading patterns within the bone, while the mechanosensitive osteocytes are of crucial importance for orchestrating the remodeling process.

Factors such as cytokines, which reduce the physiological response of osteocytes to mechanical loading, might lead to a disruption in the osteocyte-mediated balance between osteoblast and osteoclast activity thereby affecting bone mass. A reduction of cytokine levels might therefore be a priority in inflammatory diseases such as RA, not only to reduce the local deleterious effects of inflammation, but also to reduce the systemic effects on the skeleton.

\section{Future perspective}

The importance of mechanical stress for maintaining bone strength predicts that mechanical stimuli have great potential for prevention, and even treatment, of bone fractures. A logical therapeutic approach to prevent bone loss, for instance associated with osteoporosis or inflammatory diseases such as RA, would therefore be to enhance adaptive bone formation. To date, the signaling pathways activated by mechanical loading in osteocytes leading to changes in bone remodeling have been partially elucidated. One striking example is the Wnt signaling pathway, and more specifically, the inhibitor of this pathway, sclerostin. Sclerostin is a molecule that is strongly linked to bone mass disorders, and is currently under investigation for use in a clinical setting. Considering the role of the osteocytes as the professional mechanosensors of bone, and the importance of the cytoskeleton for the response of osteocytes to mechanical loading, much is to be expected from research focusing on the cytoskeletal components of the osteocyte. Moreover, future studies should be actively pursued to elucidate the molecular mechanism by which cytokines affect the osteocyte's mechanosensitivity, thereby affecting bone remodeling. However, one major limitation in current in vitro research on mechanosensing by osteocytes is the lack of multiple osteocyte cell models. Although many valid and valuable results have been obtained using models such as mechanically stimulation of cultured bonelike cells using a controlled fluid shear stress, we should keep in mind that bone cells in a 2D morphology might not always respond to this stimulus in an identical manner as cells in their unique 3D environment would. In addition, osteoblasts are often used as a surrogate for osteocytes, although there are obvious differences in, for instance, morphology. The difference between osteoblasts and osteocytes is clearly visible by looking at the unique morphological features of the osteocytes, in other words, the cell protrusions, which might be strongly related to the function of the osteocyte as mechanosensor. The many protrusions are probably of utmost importance for this mechanosensory function, although there is an ongoing discussion with regard to which part of the osteocyte, in other words, the cell body or cell fingers, are responsible for mechanosensing in vivo. A numerical study showed that application of fluid flow to cells on a 2D substrate results in maximum displacements at the apical surface of the cell body [156]. In contrast, in vivo, fluid shear stress will likely only occur over the cell processes, as the unique dimensions required for strain amplification are present in the unit made up by the cell process within its canaliculus, but not in the unit that is composed of an osteocyte cell body within its lacuna. This could be considered a major limitation of the methods currently used to study the response of bone cells to mechanical loading. Although theoretically promising, a much greater knowledge of the signal transduction pathways that govern the adaptive response of osteocytes in their natural 3D surroundings will be needed before the therapeutic option of mechanical stimuli is applicable in a clinical setting.

\footnotetext{
Acknowledgements

The authors thank Rishikesh Kulkarni for kindly providing the osteocytes/osteoclasts picture.
} 


\section{Executive summary}

\section{Bone remodeling}

- Bone adapts its mass and shape to mechanical loading.

- Mechanical adaptation of bone is facilitated by bone remodeling.

Mechanical loading drives interstitial fluid flow

- Bone loading causes matrix deformations that will result in fluid shifts within the bone matrix.

- Loading-derived fluid flow activates osteocytes.

\section{Fluid flow activates osteocytes}

- The mechanical stimulus that activates bone cells in vitro is fluid shear stress rather than streaming potentials or chemotransport.

- The mechanical stimulus for osteocytes in vivo is likely derived from strain-derived flow of interstitial fluid.

Osteocytes transduce mechanical stimuli into chemical signals

- Cytoskeletal properties of the osteocyte affect the ability for mechanosensing

- The primary cilium might play a role in the process of mechanotransduction.

\section{Osteocytes release signaling molecules in response to mechanical loading}

- An early response of osteocytes to mechanical loading is a rise in $\left[\mathrm{Ca}^{2+}\right]_{i}$.

- Upon mechanical stimulation, osteocytes release signaling factors such as nitric oxide, prostaglandins and Wnts, which can alter recruitment and activity of osteoblasts and osteoclasts.

\section{Osteocytes orchestrate osteoblast \& osteoclast activity}

- Osteocyte sensing of different loading-induced canalicular flow patterns around cutting cone and reversal zone during remodeling explains the coordinated actions of osteoblasts and osteoclasts in a basic multicellular unit.

- Mechanical loading promotes osteocyte survival, while unloading is associated with osteocyte apoptosis, which triggers osteoclastic bone resorption.

\section{The role of osteocytes in inflammation-associated bone loss}

- Cytokines might interfere with bone remodeling during inflammatory diseases via an effect on the mechanoresponse of osteocytes.

\section{Conclusion}

- Mechanosensitive osteocytes are of crucial importance for orchestrating the remodeling process in bone.

- Significant progress has been made in the uncovering of the cellular and mechanical basis of the osteocyte's response to loading, and to our understanding of cellular mechanotransduction and bone remodeling.

Financial \& competing interests disclosure

The authors have no relevant affiliations or financial involvement with any organization or entity with a financial interest in or financial conflict with the subject matter or materials discussed in the manuscript.
This includes employment, consultancies, honoraria, stock ownership or options, expert testimony, grants or patents received or pending, or royalties.

No writing assistance was utilized in the production of this manuscript.

\section{Bibliography}

Papers of special note have been highlighted as: - of interest

." of considerable interest

1. Rubin CT, Lanyon LE: Kappa Delta Award paper. Osteoregulatory nature of mechanical stimuli: function as a determinant for adaptive remodeling in bone. J. Orthop. Res. 5, 300-310 (1987).

2. Turner $\mathrm{CH}$, Owan I, Takano Y: Mechanotransduction in bone: role of strain rate. Am. J. Physiol. 269, E438-E442 (1995).

3. Van der Wiel HE, Lips P, Graafmans WC et al: : Additional weight-bearing during exercise is more important than duration of exercise for anabolic stimulus of bone: a study of running exercise in female rats. Bone 16 , 73-80 (1995).

4. Westerlind KC, Turner RT: The skeletal effects of spaceflight in growing rats: tissue-specific alterations in mRNA levels for TGF $\beta$. J. Bone Miner. Res. 10, 844-848 (1995).

5. Rubin CT, Lanyon LE: Regulation of bone formation by applied dynamic loads. J. Bone Joint Surg. Am. 66, 397-402 (1984).

6. Vico L, Alexandre C: Microgravity and bone adaptation at the tissue level. J. Bone Miner. Res. 7, S445-S447 (1992).

7. Frost HM: Bone "mass" and the "mechanostat": a proposal. Anat. Rec. 219, 1-9 (1987).

8. Smit TH, Burger EH: Is BMU-coupling a strain-regulated phenomenon? A finite element analysis. J. Bone Miner. Res. 15, 301-307 (2000).

-. Demonstrates, for the first time, that basic multicellular unit (BMU) coupling, which is the subsequent activation of osteoclasts and osteoblasts during remodeling, is a strain-regulated phenomenon.
9. Schneider P, Stauber M, Voide R, Stampanoni M, Donahue LR, Müller R: Ultrastructural properties in cortical bone vary greatly in two inbred strains of mice as assessed by synchrotron light based micro- and nano-CT. J. Bone Miner. Res. 22, 1557-1570 (2007).

10. Bentolilla V, Boyce TM, Fyhrie DB, Drumb R, Skerry TM, Schaffler MB: Intracortical remodeling in adult rat long bones after fatigue loading. Bone 23, 275-281 (1998).

11. Burr DB, Martin RB: Calculating the probability that microcracks initiate resorption spaces. J. Biomech. 26, 613-616 (1993).

12. Verborgt O, Gibson GJ, Shaffler MB: Loss of osteocyte integrity in association with microdamage and bone remodeling after fatigue in vivo. J. Bone Miner. Res. 15, 60-67 (2000).

13. Bronckers ALJJ, Goei SW, Luo G et al.: DNA fragmentation during bone formation in neonatal rodents assessed by transferase- 
mediated en labeling. J. Bone Miner. Res. 11, 1281-1291 (1996).

14. Frost HM: Bone Remodeling Dynamics. CC Thomas, Springfield, IL, USA (1963).

15. Parfitt AM: Osteonal and hemi-osteonal remodeling: the spatial and temporal framework for signal traffic in adult human bone. J. Cell. Biochem. 55, 273-286 (1994).

16. Manolagas SC: Birth and death of bone cells: basic regulatory mechanisms and implications for the pathogenesis and treatment of osteoporosis. Endocr. Rev. 21, 115-137 (2000).

17. Marotti G: The structure of bone tissues and the cellular control of their deposition. Ital. J. Anat. Embryol. 101, 25-79 (1996).

18. Cowin SC, Moss-Salentijn L, Moss ML: Candidates for the mechanosensory system in bone. J. Biomed. Eng. 113, 191-197 (1991).

19. Burger EH, Klein-Nulend J: Mechanotransduction in bone - role of the lacunocanalicular network. FASEB J. 13, S101-S112 (1999).

-. Summarizes the role of osteocytes as the professional mechanosensory cells of bone, and the lacuno-canalicular porosity as the structure that mediates mechanosensing. Local bone gain and loss, as well as remodeling in response to fatigue damage, are explained as processes supervised by mechanosensitive osteocytes.

20. Lanyon LE: Osteocytes, strain detection, bone modeling, and remodeling. Calcif. Tissue Int. (Suppl. 1), S102-S106 (1993).

21. Pienkowski D, Pollack SR: The origin of stress-generated potentials in fluid-saturated bone. J. Orthop. Res. 1, 30-41 (1983).

22. Rubin CT: Skeletal strain and the functional significance of bone architecture. Calcif. Tissue Int. 36, S11-S18 (1984).

23. Burr DB, Milgran C, Fyhrie D et al.: In vivo measurement of human tibial strains during vigorous activity. Bone 18, 405-410 (1996).

24. Vatsa A, Breuls RG, Semeins CM, Salmon PL, Smit TH, Klein-Nulend J: Osteocyte morphology in fibula and calvaria - is there a role for mechanosensing? Bone (2008) (Epub ahead of print).

-. The authors found anisotropy of osteocytes and alignment in the local mechanical loading direction, suggesting that osteocytes are able to directly sense matrix strains due to external loading of bone. The relatively spherical morphology of calvarial osteocytes suggests that these cells are more mechanosensitive than fibilar osteocytes, which provides a possible explanation for efficient load bearing for the maintenance of calvarial bone despite its condition of relative mechanical disuse.
25. Vatsa A, Semeins CM, Smit TH, KleinNulend J: Paxillin localisation in osteocytes is it determined by the direction of loading? Biochem. Biophys. Res. Commun. (2008) (Epub ahead of print).

26. Klein-Nulend J, Van der Plas A, Semeins CM et al:: Sensitivity of osteocytes to biomechanical stress in vitro. FASEB J. 9 , 441-445 (1995).

- Provides evidence that osteocytes are the most mechanosensitive cells in bone involved in the transduction of mechanical stress into a biological response. The results support the hypothesis that stress on bone causes fluid flow in the lacunar-canalicular system, which stimulates the osteocytes to produce factors that regulate bone metabolism.

27. Cowin SC, Weinbaum S, Zeng Y: A case for bone canaliculi as the anatomical site of strain generated potentials. J. Biomech. 28, 1281-1297 (1995).

28. Cowin SC: Bone poroelasticity. J. Biomech. 32, 217-238 (1999).

29. Weinbaum S, Cowin SC, Zeng Y: A model for the excitation of osteocytes by mechanical loading-induced bone fluid shear stresses. J. Biomech. 27, 339-360 (1994).

-. Experimentally testable hypothesis is advanced for the mechanosensory transduction mechanism by which communicating osteocytes sense the very small in vivo strains in the calcified matrix components of bone. The authors propose that the osteocytes, although not responsive to substantial fluid pressures, can be stimulated by relatively small fluid shear stresses acting on the membranes of their osteocytic processes.

30. Knothe-Tate ML, Steck R, Forwood MR, Niederer P: In vivo demonstration of load-induced fluid flow in the rat tibia and its potential implications for processes associated with functional adaptation. J. Exp. Biol. 203, 2737-2745 (2000).

31. You L, Cowin SC, Schaffler MB, WeinbaumS: A model for strain amplification in the actin cytoskeleton of osteocytes due to fluid drag on pericellular matrix. J. Biomech. 34, 1375-1386 (2001).

32. Piekarski K, Munro M: Transport mechanism operating between blood supply and osteocytes in long bones. Nature 269, 80-82 (1977).

33. Knothe Tate ML, Knothe U, Niederer P: Experimental elucidation of mechanical load-induced fluid flow and its potential role in bone metabolism and functional adaptation. Am. J. Med. Sci. 316, 189-195 (1998).
34. Fritton SP, McLeod KJ, Rubin CT: Quantifying the strain history of bone: spatial uniformity and self-similarity of lowmagnitude strains. J. Biomech. 33, 317-325 (2000).

35. Lanyon LE, Rubin CT: Static vs dynamic loads as an influence on bone remodelling. J. Biomech. 17, 897-905 (1984).

36. Turner $\mathrm{CH}$, Owan I, Takano Y: Mechanotransduction in bone: role of strain rate. Am. J. Physiol. 269, E438-E442 (1995).

37. Bergmann G, Graichen F, Rohlmann A: Hip joint loading during walking and running, measured in two patients. J. Biomech. 26, 969-990 (1993).

38. Bacabac RG, Smit TH, Mullender MG, Dijcks SJ, Van Loon JJWA, Klein-Nulend J: Nitric oxide production by bone cells is fluid shear stress rate dependent. Biochem. Biophys. Res. Commun. 315, 823-829 (2004).

-. Shows for the first time that the fluid shear stress rate is an important parameter for bone cell activation. The rate-dependent response of bone cells to fluid shear stress provides an explanation for the observation that the rate (determined by frequency and magnitude) of mechanical loading determines the amount of bone formation in vivo.

39. Bakker AD, Soejima K, Klein-Nulend J, Burger EH: The production of nitric oxide and prostaglandin $\mathrm{E}_{2}$ by primary bone cells is shear stress dependent. J. Biomech. 34, 671-677 (2001).

- Describes the nature of the stimulus that activates the osteocytes as a result of loading on bone. They found that flow-derived shear stress, but not streaming potentials or chemotransport, is the stimulus leading to nitric oxide and prostaglandin production in osteocyte-like cells.

40. Reich KM, Gay CV, Frangos JA: Fluid shear stress as a mediator of osteoblast cyclic adenosine monophosphate production. J. Cell. Physiol. 143, 100-104 (1990).

41. Donahue TL, Haut TR, Yellowley CE, Donahue HJ, Jacobs CR: Mechanosensitivity of bone cells to oscillating fluid flow induced shear stress may be modulated by chemotransport. J. Biomech. 36, 1363-1371 (2003).

42. Han Y, Cowin SC, Schaffler MB, Weinbaum S: Mechanotransduction and strain amplification in osteocyte cell processes. Proc. Natl Acad. Sci. USA 101, 16689-16694 (2004).

- Proposes that their strain-amplification model provides a more likely hypothesis for the excitation of osteocytes than the 
previously proposed fluid-shear hypothesis. The model predicts that the fluid flow through the pericellular matrix in the lacunar-canalicular porosity due to mechanical loading can induce strains in the actin filament bundles of the cytoskeleton that are more than an order of magnitude larger than tissue level strains.

43. Wang Y, McNamara LM, Schaffler MB, Weinbaum S: A model for the role of integrins in flow induced mechanotransduction in osteocytes. Proc. Natl Acad. Sci. USA 104, 15941-15846 (2007).

44. Hughes DE, Salter DM, Simpson R: CD 44 expression in human bone: A novel marker of osteocytic differentiation. J. Bone Miner. Res. 9, 39-44 (1994).

45. Nakamura H, Ozawa H: Immunolocalization of CD44 and the ERM family in bone cells of mouse tibiae. J. Bone Miner. Res. 11, 1715-1722 (1996).

46. Ajubi NE, Klein-Nulend J, Nijweide PJ, Vrijheid-Lammers T, Alblas MJ, Burger EH: Pulsating fluid flow increases prostaglandin production by cultured chicken osteocytes a cytoskeleton-dependent process. Biochem. Biophys. Res. Commun. 225, 62-68 (1996).

47. Wang N, Butler JP, Ingber DE: Mechanotransduction across the cell surface and through the cytoskeleton. Science 260, 1124-1127 (1993).

48. Watson PA: Function follows form: Generation of intracellular signals by cell deformation. FASEB J. 5, 2013-2019 (1991).

49. Ajubi NE, Klein-Nulend J, Alblas MJ, Burger EH, Nijweide PJ: Signal transduction pathways involved in fluid flow-induced prostaglandin $\mathrm{E}_{2}$ production by cultured osteocytes. Am. J. Physiol. 276, E171-E178 (1999).

50. Pavalko FM, Chen NX, Turner $\mathrm{CH}$ et al.: Fluid shear-induced mechanical signaling in MC3T3-E1 osteoblasts requires cytoskeleton integrin interactions. Am. J. Physiol. 275, C1591-C1601 (1998).

51. Tanaka-Kamioka K, Kamioka H, Ris H, Lim SS: Osteocyte shape is dependent on actin filaments and osteocyte processes are unique actin-rich projections. J. Bone Miner. Res. 13, 1555-1568 (1998).

- Extensive analysis of the osteocyte cytoskeleton is provided, based on the successful isolation of osteocytes from embryonic chick calvariae. They identified two actin-bundling proteins, $\alpha$-actinin and fimbrin, in osteocyte processes. The prominence and unique distribution of fimbrin in osteocyte processes provides the possibility of its use as an intracellular marker to distinguish osteocytes from osteoblasts.

52. You LD, Weinbaum S, Cowin SC, Schaffler MB: Ultrastructure of the osteocyte process and its pericellular matrix. Anat. Rec. A Discov. Mol. Cell. Evol. Biol. 278, 505-513 (2004).

53. Bacabac RG, Smit TH, Van Loon JJWA, Zandieh Doulabi B, Helder MN, KleinNulend J: Bone cell responses to highfrequency vibration stress: does the nucleus oscillate within the cytoplasm? FASEB J. 20, 858-864 (2006).

- Describes for the first time how bone cells sense vibration stress, and provide a physical basis for cellular mechanosensing of high-frequency loading.

54. Mullender MG, Dijcks SJ, Bacabac RG, Semeins CM, Van Loon JJWA, Klein-Nulend $\mathrm{J}$ : Release of nitric oxide, but not prostaglandin $\mathrm{E}_{2}$, by bone cells depends on fluid flow frequency. J. Orthop. Res. 24, 1170-1177 (2006).

55. Bacabac RG, Smit TH, Mullender MG, Van Loon JJWA, Klein-Nulend J: Initial stress-kick is required for fluid shear stress-induced rate dependent activation of bone cells. Ann. Biomed. Eng. 33, 104-110 (2005).

56. Murshid SA, Kamioka H, Ishihara Y, Ando R, Sugawara Y, Takano-Yamamoto T: Actin and microtubule cytoskeletons of the processes of 3D-cultured MC3T3-E1 cells and osteocytes. J. Bone Miner. Metab. 25, 151-158 (2007).

57. Bacabac RG, Mizuno D, Schmidt CF et al.: Round versus flat: bone cell morphology, elasticity, and mechanosensing. J. Biomech. 41, 1590-1598 (2008).

-. A new methodology was developed for investigating the rheology and mechanosensitivity of bone cells under different morphologies using atomic force microscopy and their two-particle assay for optical tweezers. Their results suggest that a round cellular morphology supports a less stiff cytoskeleton configuration compared with flat cellular morphology. This implies that osteocytes take advantage of their ellipsoid morphology in vivo to sense small strains benefiting bone health.

58. McGarry JG, Klein-Nulend J, Prendergast PJ: The effect of cytoskeletal disruption on pulsatile fluid flow-induced nitric oxide and prostaglandin $\mathrm{E}_{2}$ release in osteocytes and osteoblasts. Biochem. Biophys. Res. Commun. 330, 341-348 (2005).
59. Malone AM, Batra NN, Shivaram G et al:: The role of actin cytoskeleton in oscillatory fluid flow-induced signaling in MC3T3-E1 osteoblasts. Am. J. Physiol. Cell. Physiol. 292, C1830-C1836 (2007).

60. Sugawara Y, Ando R, Kamioka $\mathrm{H}$ et al: The alteration of a mechanical property of bone cells during the process of changing from osteoblasts to osteocytes. Bone 43, 19-24 (2008).

61. Bacabac RG, Mizuno D, Schmidt CF et al: Microrheology and force traction of mechanosensitive bone cells. J. Biomech. 39(Suppl. 1), S231-S232 (2006).

62. Zhang K, Barragan-Adjemian C, Ye L et al.: E11/gp38 selective expression in osteocytes: regulation by mechanical strain and role in dendrite elongation. Mol. Cell Biol. 26, 4539-4552 (2006).

63. Van der Plas A, Nijweide PJ: Isolation and purification of osteocytes. J. Bone Miner. Res. 7, 389-396 (1992)

64. Doty SB: Morphological evidence of gap junctions between bone cells. Calcif. Tissue Int. 33, 509-512 (1981).

65. Goodenough DA, Goliger JA, Paul DL: Connexins, connexons, and intercellular communication. Annu. Rev. Biochem. 65, 475-502 (1996).

66. Bennett MV, Goodenough DA: Gap junctions, electrotonic coupling, and intercellular communication. Neurosci. Res. Program Bull. 16, 1-486 (1978).

67. Lecanda F, Warlow PM, Sheikh S, Furlan F, Steinberg TH, Civitelli R: Connexin-43 deficiency causes delayed ossification, craniofacial abnormalities, and osteoblast dysfunction. J. Cell Biol. 151, 931-944 (2000).

68. Donahue HJ: Gap junctions and biophysical regulation of bone cell differentiation. Bone 26, 417-422 (2000).

69. Saunders MM, You J, Trosko JE, Yamasaki H, Li Z, Donahue HJ, Jacobs CR: Gap junctions and fluid flow response in MC3T3-E1 cells. Am. J. Physiol. Cell. Physiol. 281, C1917-C1925 (2001).

70. Cheng B, Zhao S, Luo J, Sprague E, Bonewald LF, Jiang JX: Expression of functional gap junctions and regulation by fluid flow in osteocyte-like MLO-Y4 cells. J. Bone Miner. Res. 16, 249-259 (2001).

71. Alford AI, Jacobs CR, Donahue HJ: Oscillating fluid flow regulates gap junction communication in osteocytic MLO-Y4 cells by an ERK1/2 MAP kinase-dependent mechanism small star, filled. Bone 33, 64-70 (2003).

72. Goodenough DA, Paul DL: Beyond the gap: functions of unpaired connexon channels. Nat. Rev. Mol. Cell Biol. 4, 285-294 (2003). 
73. Kato Y, Windle JJ, Koop BA, Mundy GR, Bonewald LF: Establishment of an osteocytelike cell line, MLO-Y4. J. Bone Miner. Res. 12, 2014-2023 (1997).

74. Genetos DC, Kephart CJ, Zhang Y, Yellowley CE, Donahue HJ: Oscillating fluid flow activation of gap junction hemichannels induces ATP release from MLO-Y4 osteocytes. J. Cell. Physiol. 212, 207-214 (2007).

75. Plotkin LI, Manolagas SC, Bellido T: Transduction of cell survival signals by connexion-43 hemichannels. J. Biol. Chem. 277, 8648-8657 (2002).

76. Cherian PP, Siller-Jackson AJ, Gu S et al.: Mechanical strain opens connexion- 43 hemichannels in osteocytes: a novel mechanism for the release of prostaglandin. Mol. Biol. Cell 16, 3100-3106 (2005).

77. Xiao Z, Zhang S, Mahlios J et al:: Cilia-like structures and polycystin-1 in osteoblasts/ osteocytes and associated abnormalities in skeletogenesis and Runx2 expression. J. Biol. Chem. 281, 30884-30895 (2006).

78. Malone AMD, Anderson CT, Tummala P et al:: Primary cilia mediate mechanosensing in bone cells by calcium-independent mechanism. Proc. Natl Acad. Sci. USA 104, 13325-13330 (2008).

- This study suggests that primary cilia might regulate homeostasis in diverse tissues by allowing mechanical signals to alter cellular activity via tissue-specific pathways. Their identification of a mechanism for mechanotransduction in bone could lead to therapeutic approaches for combating bone loss due to osteoporosis and disuse.

79. Hung CT, Pollack SR, Reilly TM, Brighton CT: Realtime calcium response of cultured bone cells to fluid flow. Clin. Orthop. Rel. Res. 313, 256-269 (1995).

80. Hung CT, Allen FD, Pollack SR, Brighton CT: Intracellular calcium stores and extracellular calcium are required in the real-time calcium response of bone cells experiencing fluid flow. J. Biomech. 29, 1411-1417 (1996).

81. Hung CT, Allen FD, Pollack SR, Brighton CT: What is the role of the convective current density in the real-time calcium response of cultured bone cells to fluid flow? J. Biomech. 29, 1403-1409 (1996).

82. Chen NX, Ryder KD, Pavalko FM et al.: $\mathrm{Ca}^{2+}$ regulates fluid shear-induced cytoskeletal reorganization and gene expression in osteoblasts. Am. J. Physiol. 278, C989-C997 (2000).

83. Genetos DC, Geist DJ, Liu D, Donahue HJ, Duncan RL: Fluid shear-induced ATP secretion mediates prostaglandin release in MC3T3-E1 osteoblasts. J. Bone Miner. Res. 20, 41-49 (2005).

84. Klein-Nulend J, Burger EH, Semeins CM, Raisz LG, Pilbeam CC: Pulsating fluid flow stimulates prostaglandin release and inducible prostaglandin $\mathrm{G} / \mathrm{H}$ synthase mRNA expression in primary mouse bone cells. J. Bone Miner. Res. 12, 45-51 (1997).

85. Nolan RD, Partridge NC, Godfrey HM, Martin TJ: Cyclo-oxygenase products of arachidonic acid metabolism in rat osteoblasts in culture. Calcif. Tissue Int. 35, 294-297 (1983).

86. Raisz LG, Pilbeam CC, Fall PM: Prostaglandins: mechanisms of action and regulation of production in bone. Osteoporos. Int. 3(Suppl. 1), 136-140 (1993).

87. Forwood MR: Inducible cyclo-oxygenase (COX-2) mediates the induction of bone formation by mechanical loading in vivo. J. Bone Miner. Res. 11, 1688-1693 (1996).

88. Chow JW, Fox SW, Lean JM, Chambers TJ: Role of nitric oxide and prostaglandins in mechanically induced bone formation. J. Bone Miner. Res. 13, 1039-1044 (1998).

89. Smith WL, Garavito RM, DeWitt DL: Prostaglandin endoperoxide $\mathrm{H}$ synthases (cyclooxygenases)-1 and -2. J. Biol. Chem. 271, 33157-33160 (1996).

90. Joldersma M, Burger EH, Semeins CM, Klein-Nulend J: Mechanical stress induces COX-2 mRNA expression in bone cells from elderly women. J. Biomech. 33, 53-61 (2000).

91. Westbroek I, Ajubi NE, Alblas MJ et al: Differential stimulation of prostaglandin $\mathrm{G} / \mathrm{H}$ synthase-2 in osteocytes and other osteogenic cells by pulsating fluid flow. Biochem. Biophys. Res. Commun. 268, 414-419 (2000).

92. Forwood MR, Kelly WL, Worth NF: Localization of prostaglandin endoperoxidase $\mathrm{H}$ synthase (PGHS)-1 and PGHS-2 in bone following mechanical loading in vivo. Anat. Rec. 252, 580-586 (1998).

93. Bakker AD, Klein-Nulend J, Burger EH: Mechanotransduction in bone cells proceeds via activation of COX-2, but not COX-1. Biochem. Biophys. Res. Commun. 305, 677-683 (2003).

94. Turner CH, Takano Y, Owan I, Murrell GA: Nitric oxide inhibitor L-NAME suppresses mechanically induced bone formation in rats. Am. J. Physiol. 270, E639-E643 (1998).

95. Fox SW, Chambers TJ, Chow JWM: Nitric oxide is an early mediator of the increase in bone formation by mechanical stimulation. Am. J. Physiol. 270, E955-E960 (1996).

96. Klein-Nulend J, Semeins CM, Ajubi NE, Nijweide PJ, Burger EH: Pulsating fluid flow increases nitric oxide (NO) synthesis by osteocytes but not periosteal fibroblastscorrelation with prostaglandin upregulation. Biochem. Biophys. Res. Commun. 217, 640-648 (1995).

97. Klein-Nulend J, Helfrich MH, Sterck JGH et al:: Nitric oxide response to shear stress by human bone cell cultures is endothelial nitric oxide synthase dependent. Biochem. Biophys. Res. Commun. 250, 108-114 (1998).

98. Pitsillides AA, Rawlinson SCF, Suswillo RFL, Bourrin S, Zaman G, Lanyon LE: Mechanical strain-induced NO production by bone cells: A possible role in adaptive bone (re)modeling? FASEB J. 9, 1614-1622 (1995).

99. Vatsa A, Smit TH, Klein-Nulend J: Extracellular NO signaling from a mechanically stimulated osteocyte. J. Biomech. 40, S89-S95 (2007).

100. Vatsa A, Mizuno D, Smit TH, Schmidt CF, MacKintosh FC, Klein-Nulend J: Bio imaging of intracellular $\mathrm{NO}$ production in single bone cells after mechanical stimulation. J. Bone Miner. Res. 21, 1722-1728 (2006).

- This study shows the intracellular upregulation of NO production after mechanical stimulation, an essential chemical signal in bone remodeling. This is done using the fluorescent chromophore DAR-4M AM. Differences in cellular response to mechanical stimulation of different regions of a single cell were observed. This technique opens up the possibility to uncover the complexities and function of single osteocytes in the dynamic process of bone remodeling.

101. Zaman G, Pitsillides AA, Rawlinson SC et al: Mechanical strain stimulates nitric oxide production by rapid activation of endothelial nitric oxide synthase in osteocytes. J. Bone Miner. Res. 14, 1123-1131 (1999).

102. Logan CY, Nusse R: The Wnt signaling pathway in development and disease. Annu. Rev. Cell. Dev. Biol. 20, 781-810 (2004).

103. Bhanot P, Brink M, Samos CH et al.: A new member of the frizzled family from Drosophila functions as a Wingless receptor. Nature 382, 225-230 (1996).

104. Tamai K, Semenov M, Kato Y et al.: LDL-receptor-related proteins in Wnt signal transduction. Nature 407, 530-535 (2000).

105. Slusarski DC, Corces VG, Moon RT: Interaction of Wnt and a Frizzled homologue triggers G-protein-linked phosphatidylinositol signaling. Nature 390, 410-413 (1997).

106. Habas R, Dawid IB, He X: Coactivation of Rac and Rho by Wnt/Frizzled signaling is required for vertebrate gastrulation. Genes Dev. 17, 295-309 (2003). 
107. Johnson ML, Harnish K, Nusse R, Van Hul W: LRP5 and Wnt signaling: a union made for bone. J. Bone Miner. Res. 19, 1749-1757 (2004).

108. Lories RJ, Peeters J, Bakker AD et al.: Articular cartilage and biomechanical properties of the long bones in Frzb-knockout mice. Arthritis Rheum. 56, 3881-3883 (2007).

109. Robinson JA, Chatterjee-Kishore M, Yaworsky PJ et al.: Wnt/ $\beta$-catenin signaling is a normal physiological response to mechanical loading in bone. J. Biol. Chem. 281, 31720-31728 (2006).

110. Santos A, Bakker AD, Zandieh-Doulabi B, Semeins CM, Klein-Nulend J: Pulsating fluid flow modulates gene expression of proteins involved in Wnt signaling pathways in osteocytes. Presented at: Transactions of the 54th Annual Meeting, Orthopaedic Research Society. San Francisco, CA, USA, 2-5 March 2008 (Abstract 0160).

111. Van Bezooijen RL, Roelen BA, Visser A et al.: Sclerostin is an osteocyte-expressed negative regulator of bone formation, but not a classical BMP antagonist. J. Exp. Med. 199, 805-814 (2004).

112. Poole KE, van Bezooijen RL, Loveridge N et al: Sclerostin is a delayed secreted product of osteocytes that inhibits bone formation. FASEB J. 19, 1842-1844 (2005).

113. Balemans W, Ebeling $M$, Patel $\mathrm{N}$ et al.: Increased bone density in sclerosteosis is due to the deficiency of a novel secreted protein (SOST). Hum. Mol. Genet. 10, 537-543 (2001).

114. Robling AG, Niziolek PJ, Baldridge LA et al.: Mechanical stimulation of bone in vivo reduces osteocyte expression of Sost/ sclerostin. J. Biol. Chem. 283, 5866-5875 (2008).

115. Gowen LC, Petersen DN, Mansolf AL et al.: Targeted disruption of the osteoblast/ osteocyte factor 45 gene (OF45) results in increased bone formation and bone mass. J. Biol. Chem. 278, 1998-2007 (2003).

116. Gluhak-Heinrich J, Yang W, Bonewald L, Robling AG, Turner $\mathrm{CH}$, Harris SE: Mechanically induced DMP1 and MEPE expression in osteocytes: correlation to mechanical strain, osteogenic response and gene expression threshold. J. Bone Miner. Res. 20, S73 (2005).

117. Toyosawa S, Shintani S, Fujiwara T et al.: Dentin matrix protein 1 is predominantly expressed in chicken and rat osteocytes but not in osteoblasts. J. Bone Miner. Res. 16, 2017-2026 (2001).

118. Feng JQ, Ward LM, Liu S et al: : Loss of DMP1 causes rickets and osteomalacia and identifies a role for osteocytes in mineral metabolism. Nat. Genet. 38, 1310-1315 (2006).

119. Gluhak-Heinrich J, Ye L, Bonewald LF et al.: Mechanical loading stimulates dentin matrix protein 1 (DMP1) expression in osteocytes in vivo. J. Bone Miner. Res. 18, 807-817 (2003).

120. Harris SE, Gluhak-Heinrich J, Harris MA et al:: DMP1 and MEPE expression are elevated in osteocytes after mechanical loading in vivo: theoretical role in controlling mineral quality in the perilacunar matrix. J. Musculoskelet. Neuronal Interact. 7, 313-315 (2007).

121. Ruchon AF, Tenenhouse HS, Marcinkiewicz M et al.: Developmental expression and tissue distribution of Phex protein: effect of the Hyp mutation and relationship to bone markers. J. Bone Miner. Res. 15, 1440-1450 (2000).

122. Rawadi G, Vayssière B, Dunn F, Baron R, Roman-Roman S: BMP-2 controls alkaline phosphatase expression and osteoblast mineralization by a Wnt autocrine loop. J. Bone Miner. Res. 18, 1842-1853 (2003).

123. Ke HZ, Jee WS: Effects of daily administration of prostaglandin E2 and its withdrawal on the lumbar vertebral bodies in male rats. Anat. Rec. 234, 172-182 (1992).

124. Li J, Burr DB , Turner CH: Supression of prostaglandin synthesis with NS-398 has different effects on endocortical ond periosteal bone formation induced by mechanical loading. Calcif. Tissue Int. 70 , 320-329 (2002).

125. Glass DA 2nd, Bialek P, Ahn JD et al:: Canonical Wnt signaling in differentiated osteoblasts controls osteoclast differentiation. Dev. Cell. 8, 751-764 (2005).

126. MacIntyre I, Zaidi M, Towhidul Alam ASM et al:: Osteoclastic inhibition: An action of nitric oxide not mediated by cyclic GMP. Proc. Natl Acad. Sci. USA 88, 2936-2940 (1991).

127. Vezeridis PS, Semeins CM, Chen Q, Klein-Nulend J: Osteocytes subjected to pulsating fluid flow regulate osteoblast proliferation and differentiation. Biochem. Biophys. Res. Commun. 348, 1082-1088 (2005).

- Osteocytes subjected to mechanical loading by fluid flow inhibit proliferation but stimulate differentiation of osteoblasts in vitro via soluble factors. The release of these soluble factors was dependent on the activation of an NO pathway in osteocytes in response to loading. The osteocyte appeared to be more responsive to pulsating fluid flow than the osteoblast or fibroblast with respect to the production of soluble signaling molecules affecting osteoblast proliferation and differentiation.

128. Taylor AF, Saunders MM, Shingle DL, Cimbala DL, Zhou Z, Donahue HJ: Mechanically stimulated osteocytes regulate osteoblastic activity via gap junctions. Am. J. Physiol. Cell Physiol. 61, C545-C304 (2007).

129. Zhao S, Zhang YK, Harris S, Ahuja SS, Bonewald LF: MLO-Y4 osteocyte-like cells support osteoclast formation and activation. J. Bone Miner. Res. 17, 2068-2079 (2002).

130. You L, Temiyasathit S, Lee P et al.: Osteocytes as mechanosensors in the inhibition of bone resorption due to mechanical loading. Bone 42, 172-179 (2008).

131. Tan SD, de Vries TJ, Kuijpers-Jagtman AM, Semeins CM, Everts V, Klein-Nulend J: Osteocytes subjected to fluid flow inhibit osteoclast formation and bone resorption. Bone 41, 745-751 (2007).

- Osteocytes subjected to mechanical loading by fluid flow inhibit osteoclast formation and resorption via soluble factors, and the release of these factors was dependent on activation of an NO pathway in osteocytes in response to mechanical loading. The osteocyte appeared to be more responsive to fluid flow than the osteoblast or fibroblast regarding the production of soluble factors affecting osteoclast formation and bone resorption.

132. Burger EH, Klein-Nulend J, Smit TH: Strain-derived canalicular fluid flow regulates osteoclast activity in a remodelling osteon-a proposal. J. Biomech. 36, 1453-1459 (2003).

- A proposal is described in which alignment during remodeling occurs as a result of different canalicular flow patterns around cutting cone and reversal zone during loading. Treadmilling of attaching and detaching osteoclasts in the tip and the periphery of the cutting cone leads to the digging of a tunnel in the direction of loading.

133. Smit TH, Burger EH, Huyghe JM: 2002 A case for strain-induced fluid flow as a regulator of BMU-coupling and osteonal alignment. J. Bone Miner. Res. 17, 2021-2029 (2002).

- The authors show that cellular activity at a bone remodeling site is well related to local fluid flow patterns, which may explain the coordinated progression of a BMU.

134. Bakker AD, Klein-Nulend J, Burger EH: Shear stress inhibits while disuse promotes osteocyte apoptosis. Biochem. Biophys. Res. Commun. 320, 1163-1168 (2004). 
135. Basso N, Heersche JNM: Effects of hind limb unloading and reloading on nitric oxide synthase expression and apoptosis of osteocytes and chondrocytes. Bone 39, 807-814 (2006).

136. Bidwell JP, Yang J, Robling AG: Is HMGB1 an osteocyte alarmin? Cell Biochem. 103, 1671-1680 (2008).

137. Kogianni G, Mann V, Noble BS: Apoptotic bodies convey activity capable of initiating osteoclastogenesis and localized bone destruction. J. Bone Miner. Res. 23, 915-927 (2008).

138. Van Oers RF, Ruimerman R, Tanck E, Hilbers PA, Huiskes R: A unified theory for osteonal and hemi-osteonal remodeling. Bone 42, 250-259 (2008).

139. Tatsumi S, Ishii $\mathrm{K}$, Amizuka $\mathrm{N}$ et al.: Targeted ablation of osteocytes induces osteoporosis with defective mechanotransduction. Cell Metab. 5 , 464-475 (2007).

-. 'Osteocyte-less' mice were shown to be resistant to unloading-induced bone loss, providing evidence for the role of osteocytes in mechanotransduction.

140. Cheng S, Sipila S, Taaffe DR, Puolakka J, Suominen H: Change in bone mass distribution induced by hormone replacement therapy and high-impact physical exercise in post-menopausal women. Bone 31, 126-135 (2002).

141. Kohrt WM, Snead DB, Slatopolsky E, Birge SJ Jr: Additive effects of weight-bearing exercise and estrogen on bone mineral density in older women. J. Bone Miner. Res. 10, 1303-1311 (1995).

142. Chow J, Tobias JH, Colston KW, Chambers TJ: Estrogen maintains trabecular bone volume in rats not only by suppression of bone resorption but also by stimulation of bone formation. J. Clin. Invest. 89, 74-78 (1992).

143. Turner RT, Riggs BL, Spelsberg TC: Skeletal effects of estrogen. Endocr. Rev. 15, 275-300 (1994).

144. Lanyon L, Skerry T: Postmenopausal osteoporosis as a failure of bone's adaptation to functional loading: a hypothesis. J. Bone Miner. Res. 16, 1937-1947 (2001).
145. Jagger CJ, Chow JW, Chambers TJ: Estrogen suppresses activation but enhances formation phase of osteogenic response to mechanical stimulation in rat bone. J Clin. Invest. 98, 2351-2357 (1996).

146. Tromp AM, Bravenboer N, Tanck E et al.: Additional weight bearing during exercise and estrogen in the rat: the effect on bone mass, turnover, and structure. Calcif. Tissue Int. 79, 404-415 (2006).

147. Lee K, Jessop H, Suswillo R, Zaman G, Lanyon L: Endocrinology: bone adaptation requires oestrogen receptor- $\alpha$. Nature 424 , 389 (2003).

148. Zaman G, Jessop HL, Muzylak M et al.: Osteocytes use estrogen receptor $\alpha$ to respond to strain but their Er $\alpha$ content is regulated by estrogen. J. Bone Miner. Res. 21, 1297-306 (2006).

149. Bakker AD, Klein-Nulend J, Tanck E, Albers GH, Lips P, Burger EH: Additive effects of estrogen and mechanical stress on nitric oxide and prostaglandin E2 production by bone cells from osteoporotic donors. Osteoporos. Int. 16, 983-989 (2005).

150. Haugeberg G, Uhlig T, Falch JA, Halse JI, Kvien TK: Bone mineral density and frequency of osteoporosis in female patients with rheumatoid arthritis: results from 394 patients in the Oslo County rheumatoid arthritis register. Arthritis Rheum. 43, 522-530 (2000).

151. Lane NE, Pressman AR, Star VL, Cummings SR, Nevitt MC: Rheumatoid arthritis and bone mineral density in elderly women. The Study of Osteoporotic Fractures Research Group. J. Bone Miner. Res. 10, 257-263 (1995).

152. Bettica P, Cline G, Hart DJ, Meyer J, Spector TD: Evidence for increased bone resorption in patients with progressive knee osteoarthritis: longitudinal results from the Chingford study. Arthritis Rheum. 46, 3178-3184 (2002).

153. Lodder MC, Haugeberg G, Lems WF et al.: Radiographic damage associated with low bone mineral density and vertebral deformities in rheumatoid arthritis: the Oslo-Truro-Amsterdam (OSTRA) collaborative study. Arthritis Rheum. 49, 209-215 (2003).
154. Bingham CO 3rd: The pathogenesis of rheumatoid arthritis: pivotal cytokines involved in bone degradation and inflammation. J. Rheumatol. (Suppl. 65), 3-9 (2002).

155. Bakker AD, da Silva VC, Semeins CM, Cirelli JA, Marcantonio RA, Klein-Nulend J. TNF $\alpha$ and IL- $1 \beta$ modulate the response of bone cells to fluid shear stress. Presented at: Transactions of the 54 th Annual Meeting, Orthopaedic Research Society. San Francisco, CA, USA, 2-5 March 2008 (Abstract 1178).

156. McGarry JG, Klein-Nulend J, Mullender MG, Prendergast PJ: A comparison of strain and fluid shear stress in stimulating bone cell responses - a computational and experimental study. FASEB J. 19, 482-484 (2005).

- The authors developed a biomechanical model of an adherent cell, to test the hypothesis that bone cells respond differently to 0.6 Pa fluid shear stress and $1000 \mathrm{mu}$ (epsilon) substrate strain stimulation because of qualitative and quantitative differences in the cellular deformation caused. Their results show independent roles for fluid flow and strain as mechanical stimuli and highlight the importance of deformation on a cellular level in bone physiology.

\section{Website}

201. Seo HS, Bromage TG: 3D evaluation of comparative osteocyte lacunar density. Abstract 2852 (Accessed 5 August 2008). http://iadr.confex.com/iadr/2007orleans/ techprogram/abstract_90784.htm

\section{Affiliations}

- Jenneke Klein-Nulend

ACTA-Vrije Universiteit, Department of Oral Cell Biology, Van der Boechorststraat 7, NL-1081 BT, Amsterdam,

The Netherlands

Tel.: +31 204448660

Fax: +31 204448683

j.kleinnulend@vumc.nl

- Astrid D Bakker

Department of Oral Cell Biology,

ACTA-Universiteit van Amsterdam and Vrije Universiteit, Research Institute MOVE, Amsterdam, The Netherlands 